\section{Smoking and Atherosclerosis}

SIR,-Your leader (26 March, p. 755) is a fair comment on the present uncertainty with regard to the effects of smoking on the coronary arteries. "On balance," you state, " the evidence is in favour of smoking being a cause, but it is still incomplete, and it would be greatly strengthened if the physiological and biochemical effects of smoking could be shown to contribute to the development of some parts of the disease process."

In a paper published earlier this year ${ }^{1}$ it was shown how heavy smokers depend, in certain cases, on their nicotine consumption to maintain their blood sugar level within normal limits. When these people attempted to break with the habit they developed hypoglycaemic symptoms, and to counteract this they ate sweets in a quantity that was surprising even to themselves.

Recently it has been reported by several workers that refined carbohydrates increase the tendency of the blood platelets to stick to the arterial walls. If nicotine is interchangeable with the refined carbohydrates in maintaining the blood sugar on comfortable levels, is it not plausible that it can also cause an increased platelet stickiness in a similar way ? To give this hypothesis a biochemical backing, it is known that nicotine exerts an antidiuretic effect due to its action on the hypothalamus. In a present, as yet unpublished, series of tests it was found that the excessive ingestion of glucose or sucrose by carbohydrate-deprived subjects may inhibit for more than four hours the diuresis that is normally expected following the drinking of a litre of water.-I am, etc.,

$$
\begin{aligned}
& \text { Sertford County Hospital, } \\
& \text { Hertford. }
\end{aligned}
$$

REFERENCB

' Szanto, S., f. Irish med. Assoc., 1966, 343, 22.

\section{One Year's Advertisements}

SIR,-Normally only the "knockers" appear to get prominence in print. Thus Mr. C. A. Pitt-Steele's letter (19 March, p. 740) came as an honest fresh breath amid the perennial pompous prattlings of the pedagogues. Here is the true humility of the scientific approach. We can all learn something, however small, from every advertisement or piece of literature. Was our training so poor, or now forgotten, that we cannot sort out the wheat of fact from the chaff of advertising gimmickry?

It is stupid to damn all advertising as useless. Many of our pharmaceutical companies produce not only excellent products but extremely helpful aids.

Observe the recent hand-out for a urinarytract infection treatment. This is combined with an admirable, detachable, patientinstruction card for producing a "clean catch" specimen.

Now that the importance of this problem is becoming recognized the dangerous fallacy of routine "sulphas for cystitis" is being exposed, ${ }^{1}$ and the trap of easy symptomatic amelioration without infection eradication is being revealed. It is folly to waste the advantages of bacteriological control by submitting anything other than properly produced specimens. How much precious time have we been saved by these cards? Bacteriologists must be equally grateful.

Surely this is the type of advertisement against which routine denigration is ridiculous. Yet grudging or indeed any gratitude is never expressed.

Instead of complaining and condemning, why don't we praise the good and useful ? Train and encourage advertisers by constructive criticism to produce what we want in the form to help us, and thus our patients, most.-I am, etc.,

$$
\begin{gathered}
\text { Frampton Cotterell, } \\
\text { Bristol. }
\end{gathered}
$$

\section{REFERENCE}

1 J. Coll. gen. Practit., 1965, 10, Supp. 1.

\section{Improved Cusco's Vaginal Speculum}

SIR,-The increased use of vaginal cytology has called attention to the defects of the usually available vaginal specula, and in particular their shortnes. Lengthened forms of some models have been made in recent years, but the Cusco bivalve speculum is a convenient one, as it gives a good view of the cervix while leaving both hands free, and it can be used with the patient in the left lateral position.

As the standard narrow models are too short, however, to show the cervix satisfactorily in most patients, one with the posterior blade lengthened to $5 \frac{1}{4}$ in. $(13 \mathrm{~cm}$.) has been made for me by Messrs. Charles Thackray, of Leeds. This has proved very satisfactory for the taking of cervical smears, and it might also be useful for other purposes such as the insertion of intrauterine contraceptive devices.-I am, etc.,

Middlesbrough.

BRYAN WILLIAMs.

\section{Working Capacity of Women Doctors}

SIR,-I am very surprised to see that the important article (12 February, p. 409) on the working capacity of women doctors has evoked so little response at this time when a shortage of doctors is so much in the news.

It is noticeable that among women doctors there is a demand for part-time work. This is no doubt made in the belief that parttime work is easier, and that one's home and family are not neglected in favour of one's profession, which it looks bad to give up. The increasing complexity of modern medicine necessitates that a more than dilettante effort is made to keep up appropriate skills. In fact, it is not very much easier to work only part-time if enough is done to make it more than a hobby. As a reliable system is fundamental to being able to give one's mind to the job, a comparable amount of domestic organization must be made whether full- or part-time work is attempted.

Some $40 \%$ of women qualified since 1950 are apparently working less than five sessions or not at all, ${ }^{1}$ and one wonders what is the principle of selection for training in medical schools. To judge from letters appearing annually in the national press, girls are chosen who have the highest academic qualifications; an apparently democratic method for filling a limited number of places from many applicants. Can it be that the ability to obtain high grades at A-level and glowing testimonials from a headmistress indicate docility rather than fitness to qualify in medicine, sustain an arduous professional life, and choose in marriage someone who will not expect the profession to be relinquished ? So many girls are trained at public expense that serious efforts should be made to discover which qualities in an applicant indicate that she will persist in the practice of medicine.

A suitable point of entry into the problem might be a retrospective study of the entrance qualifications, and any records of impressions gained at interview of those married women who are now in full-time practice. -I am, etc.,

London, S.E.27.

Frances Margaret Ulyatt.

REFERENCE Knowelden, J., and Lunn, J. E., Brit. med. F.,
1966, 1, 610.

\section{Merit Awards for General Practitioners}

SIR,-The merit award proposals for general practitioners that are currently under discussion appear to me to be directly contrary to the real needs of general practice, and should be entirely discarded. Many excellent points have been made to support the rejection of these proposals, and those in favour have been few and nebulous.

Lord Taylor, in an important investigation ${ }^{1}$ into the state of general practice some years ago, pointed out that in areas of high morbidity the items of service were as high as nine per patient per year; whereas in areas of low morbidity this factor was as low as two items of service.

The average life expectancy of the doctor is now 62 years; the nine-items-of-service doctor may look forward to premature death in harness after a life of grinding and unrelenting pressure in an unattractive industrial area. The more fortunate doctor practising in an area of low morbidity performing two items of service may look forward to a pleasant enough professional life, with the prospect of surviving until retirement, and with sufficient time to devote to meritorious projects, spiced no doubt with the attractions of living in a pleasant area.

I belong to neither of these two groups, but it would appear to me to be quite clear if there is any extra money available where it should be destined.

It is quite impossible for practitioners in areas of high morbidity to devote time to merit-worthy activities, and it is a brutal insult to many who are so hard-pressed to divert extra money as merit awards to those who are already fortunate in their practice location and light work load.

The suggestion that merit awards to a favoured few would raise the overall standard in general practice is based on an incomplete and incompetent appraisal of the present realities of general practice.

If the merit award proposals are accepted, this will undoubtedly increase rather than decrease the great variations in the quality of care. This variation of quality is in the main due to the variations of work load that the individual doctor has to face. This extra money in the shape of merit awards will be going to doctors who need it the least.

It will further increase the bitterness, hostility, and suspicion between the administra- 